\title{
Взаимосвязь структуры термообработанных талько-хлоритовых сланцев со свойствами жаростойких бетонов
}

\author{
Бастрыгина С.В., Беляевский А.Т.
}

Институт химии и технологии редких элементов и минерального сырья им. И.В. Тананаева

КНЦPAH, Anamumbl, bastr_sv@chemy.kolasc.net.ru

Аннотация. Представлены результаты исследований талько-хлоритовых сланцев месторождения Калиево-Муренанваара Республики Карелия. Показаны структурные изменения сланцев при термообработке в интервале температур $900-1050^{\circ} \mathrm{C}$ и их влияние на физико-химические свойства. Установлены зависимости основных свойств жаростойких бетонов от температуры обжига заполнителя. Результаты подтверждены исследованием микроструктуры бетонов в проектном возрасте и после обжига.

Ключевые слова: талько-хлоритовый сланец, термообработка, жаростойкий бетон, структура, свойства.

\section{The relationship of the structure of heat-treated talc-chlorite shales with the properties of heat-resistant concrete}

\author{
Bastrygina S.V., Belyaevsky A.T. \\ Tananaev Institute of Chemistry-Subdivision of the Federal Research Centre KSC RAS, Apatity, \\ bastr_sv@chemy.kolasc.net.ru
}

\begin{abstract}
The results of studies of talc-chlorite schists from the Kalievo-Murenanvaara deposit in the Republic of Karelia are presented. The structural changes of shale during heat treatment in the temperature range $900-1050{ }^{\circ} \mathrm{C}$ and their influence on the physicochemical properties are shown. The dependences of the main properties of heatresistant concretes on the roasting temperature of the aggregate have been established. The results are confirmed by the study of the microstructure of concrete at the project age and after firing.
\end{abstract}

Keywords: talc-chlorite shale, heat treatment, heat-resistant concrete, structure, properties.

Талько-хлоритовые сланцы являются ценным минеральным сырьем Республики Карелия. Благодаря своим уникальным свойствам (экологическая чистота, высокая теплоемкость, термостойкость, низкая теплопроводность), они могут найти широкое применение в различных отраслях промышленности: для футеровки вращающихся обжиговых печей и катодного устройства алюминиевых электролизеров, керамических материалов и ряда других (Соколов В.И. и др., 1993,1995, Ильина и др., 2005, 2009). ООО «Горизонт» успешно использует сланцы для облицовки каменных и печных топок, банных печей, теплых полов, душевых кабин, бассейнов и т.д. При добыче сланцев образуется большое количество отходов фракции менее 40 мм. Одним из возможных путей утилизации этих отходов является их использование в качестве заполнителя жаростойких бетонов. Указанные бетоны должны удовлетворять требованиям ГОСТ 20910-90 на жаростойкие бетоны и иметь температуру применения не менее $1000^{\circ} \mathrm{C}$.

Для проведения исследований использовали пробу талько-хлоритового сланца (ТХС), отобранную на месторождении Калиево-Муренанваара Республики Карелия. По данным разведочных работ сланец имеет состав: тальк - 45-46\%, хлорит - 32-35\%, карбонаты (брейнерит, доломит, магнезит) - 18-27 \%, рудные минералы - до 3 \%. Проба предварительно подвергалась дроблению на щековой лабораторной дробилке, затем просеивалась через стандартный набор сит на фракции 5-10 и менее 5 мм.

При разработке технологии получения жаростойких материалов из сланцев необходимо знать условия их термообработки, а также свойств, приобретаемых породой во время обжига. Предпосылкой проведения этих испытаний послужили результаты исследований свойств талько-хлоритовых сланцев и продуктов их обжига, которые показали, что сланцы, обожженные при температуре 900-1000 ${ }^{\circ} \mathrm{C}$ характеризуются высокой прочностью, термостойкостью и обладают хорошими теплозащитными свойствами (Соколов В.И., 1995). 

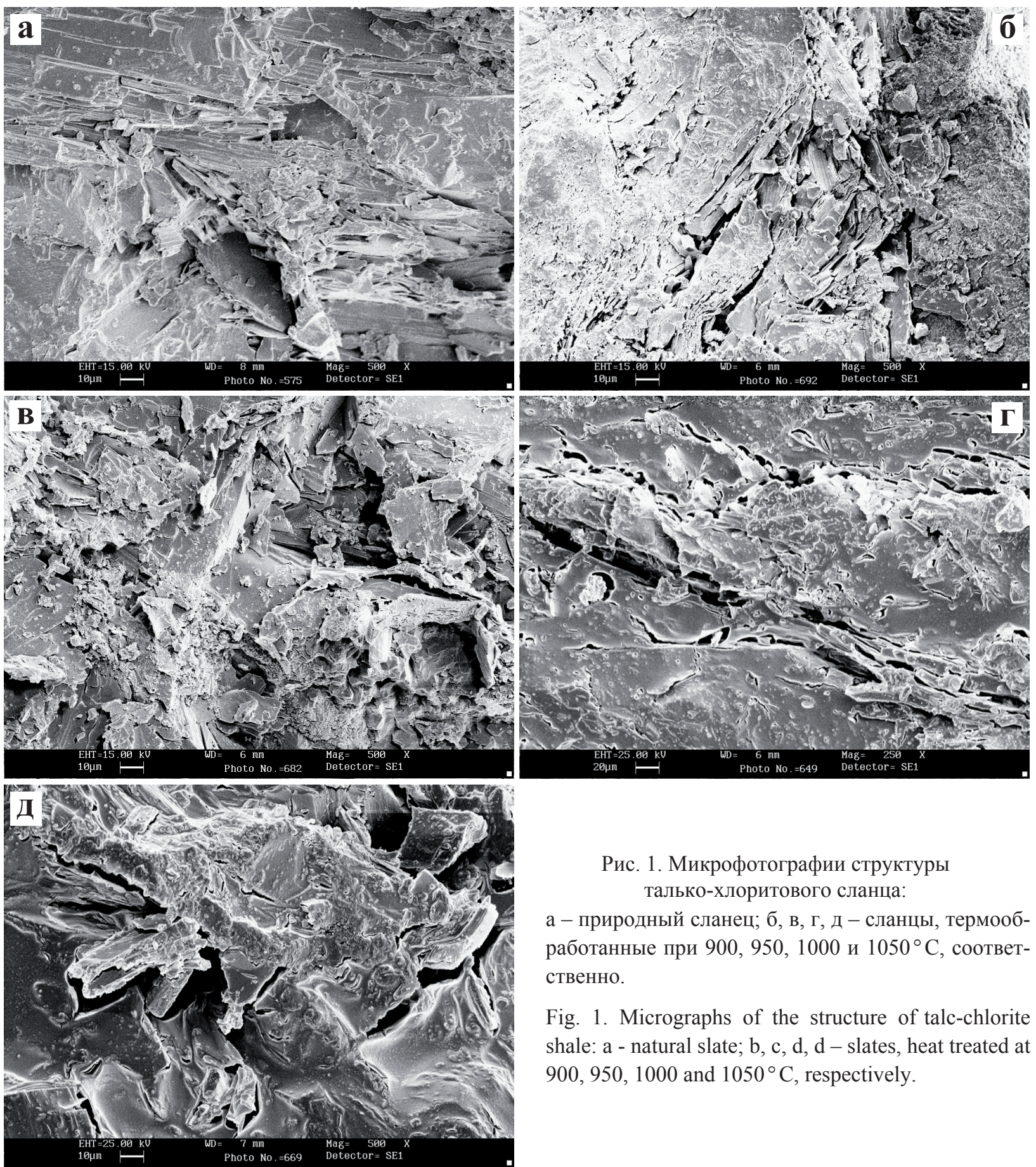

Рис. 1. Микрофотографии структуры талько-хлоритового сланца:

a - природный сланец; б, в, г, д - сланцы, термообработанные при 900, 950, 1000 и $1050^{\circ} \mathrm{C}$, соответственно.

Fig. 1. Micrographs of the structure of talc-chlorite shale: a - natural slate; $b, c, d, d$ - slates, heat treated at $900,950,1000$ and $1050{ }^{\circ} \mathrm{C}$, respectively.

Обжиг сланцев проводился в лабораторной печи LF-7/13-G1 с модулем управления TS87B. Образцы помещали в разогретую до требуемых температур печь $\left(900-1050^{\circ} \mathrm{C}\right.$ с интервалом $\left.50^{\circ} \mathrm{C}\right)$ и выдерживали в ней 20 мин.

Структура сланцев, обожженных при различных температурах, изучалась с помощью цифрового сканирующего электронного микроскопа SEM LEO-420 и представлена на рисунке 1.

На микрофотографии скола образца природного сланца (рис. 1, а) отчетливо видна пластинчатая структура талька в сростках с хлоритом, имеющего листовато-чешуйчатую структуру.

С увеличением температуры структура сланцев меняется. При температуре $900^{\circ} \mathrm{C}$ (рис. 1, б) по границам их зерен начинают образовываться поры. Они имеют вид каналов неправильной формы, длиной нескольких десятков микрон и шириной до 2 мкм. С увеличением температуры нагрева раскрытие трещин возрастает. На микрофотографиях, соответствующих температуре обжига слан- 
цев 950- $1050^{\circ} \mathrm{C}$ (рис. 1, в, г, д) хорошо видно, что для данного участка образца характерно наличие как крупных пор, представленных в основном микротрещинами, так и пор малого размера, занимающих значительную долю порового объема.

Структурные преобразования, сопровождающие нагрев талько-хлоритовых сланцев оказывают существенное влияние и на химический состав продуктов их обжига (табл. 1). В результате выноса части вещества и окисления железа при нагреве сланцев изменяется относительное содержание отдельных элементов. Это характерно для окисного и закисного железа, что значительно влияет на некоторые физические свойства термообработанной породы.

Таблица 1. Химический состав термообработанных сланцев.

Table 1. The chemical composition of heat-treated shale.

\begin{tabular}{|c|c|c|c|c|c|c|c|c|c|c|c|c|}
\hline \multicolumn{13}{|c|}{ Содержание оксидов, мас.\% } \\
\hline $\mathrm{SiO}_{2}$ & $\mathrm{Al}_{2} \mathrm{O}_{3}$ & $\mathrm{Fe}_{2} \mathrm{O}_{3}$ & $\mathrm{FeO}$ & $\mathrm{CaO}$ & $\mathrm{MgO}$ & $\mathrm{TiO}_{2}$ & $\mathrm{MnO}$ & $\mathrm{Na}_{2} \mathrm{O}$ & $\mathrm{K}_{2} \mathrm{O}$ & $\mathrm{SO}_{3}$ & $\mathrm{C}$ & п.П.П. \\
\hline \multicolumn{13}{|c|}{ Исходный } \\
\hline 36.23 & 6.23 & 9.91 & 4.40 & 7.72 & 24.60 & 0.30 & 0.16 & 0.12 & 0.10 & 0.24 & 1.46 & 9.78 \\
\hline \multicolumn{13}{|c|}{$900^{\circ} \mathrm{C}$} \\
\hline 42.15 & 6.52 & 11.35 & 0.73 & 7.32 & 27.04 & 0.24 & 0.18 & 0.11 & 0.13 & 0.21 & 0.06 & 0.66 \\
\hline \multicolumn{13}{|c|}{$950^{\circ} \mathrm{C}$} \\
\hline 43.12 & 6.54 & 11.35 & 0.60 & 7.02 & 27.06 & 0.25 & 0.18 & 0.11 & 0.13 & 0.16 & 0.06 & 0.47 \\
\hline \multicolumn{13}{|c|}{$1000^{\circ} \mathrm{C}$} \\
\hline 43.45 & 6.63 & 11.67 & 0.55 & 6.80 & 27.14 & 0.25 & 0.19 & 0.11 & 0.14 & 0.16 & 0.04 & 0.43 \\
\hline \multicolumn{13}{|c|}{$1050^{\circ} \mathrm{C}$} \\
\hline 43.58 & 6.15 & 11.72 & 0.50 & 6.60 & 27.45 & 0.25 & 0.18 & 0.11 & 0.13 & 0.15 & - & - \\
\hline
\end{tabular}

Так с увеличением температуры обжига с 900 до $1050^{\circ} \mathrm{C}$ за счет диссоциации и дегидратации минералов плотность сланцев уменьшается на 15-22\%, а пористость возрастает до 14-21\%. Оптимальной температурой обжига следует считать $1000^{\circ} \mathrm{C}$, т.к. при этой температуре отмечается некоторое сокращение пористости, водопоглощения и значительное снижение значений коэффициента теплопроводности сланцев, что обусловлено ростом объема порового пространства, представленного закрытыми порами.

Природные сланцы обладают в основном невысокой прочностью, что обусловлено степенью их рассланцевания и составом. Обжиг сланцев оказывает существенное влияние на их прочность. Как показывают наши данные, максимальную прочность имеют сланцы, обожженные при $1000^{\circ} \mathrm{C}$, что связано с протеканием химических реакций в твердой фазе, сопровождающихся образованием метасиликата магния при перестройке кристаллической решетки талька. При дальнейшем повышении температуры эта тенденция нарушается в результате разложения талька, что способствует увеличению пористости, ослаблению связей и уменьшению прочности. Изменение структуры и свойств термообработанных сланцев должно отразиться и на свойствах жаростойкого бетона.

При подборе составов бетона в качестве заполнителя использовался щебень фракции 5-10 мм из талько-хлоритовых сланцев, обожженных при различных температурах. Для бетона контрольного состава использовался необожженный талько-хлоритовый щебень того же зернового состава. Мелким заполнителем служили отсевы дробления сланцев фракции менее 5 мм, обожженные - для основного состава, и необожженные - для контрольного. В качестве вяжущего использовался порт-

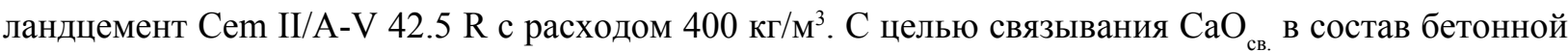
смеси вводили золошлаковую смесь (ЗШС) в количестве $30 \%$ от массы цемента.

Основные свойства полученных бетонов приведены в таблице 2. Установлено, что плотность бетона на термообработанных сланцах на 10-12\% меньше, чем на исходных. В результате термообработки сланцы приобретают шероховатую поверхность, которая обеспечивает хорошее сцепление между цементным камнем и заполнителем, а значительная деформативность способствует уменьшению отрицательного влияния на структуру бетона усадки цементного камня. 
Таблица 2. Основные свойства жаростойких бетонов на основе термообработанных сланцев.

Table 2. The main properties of heat-resistant concretes based on heat-treated shale.

\begin{tabular}{|l|c|c|c|c|}
\hline \multirow{2}{*}{ Свойства бетона } & \multicolumn{4}{|c|}{ Температура обжига сланцев, ${ }^{\circ} \mathrm{C}$} \\
\cline { 2 - 5 } & исх. & 950 & 1000 & 1050 \\
\hline $\begin{array}{l}\text { Прочность при сжатии, МПа: } \\
\text { - после ТВО } \\
\text { - после 28 сут. }\end{array}$ & 20.3 & 16.4 & 19.9 & 17.4 \\
\hline Средняя плотность, кг $/ \mathrm{M}^{3}$ & 26.1 & 24.4 & 28.9 & 25.6 \\
\hline Остаточная прочность, \% при $800^{\circ} \mathrm{C}$ & 2220 & 2010 & 2060 & 1960 \\
\hline Усадка, \%: & 43.0 & 44.7 & 58.6 & 45.9 \\
при $800^{\circ} \mathrm{C}$ & & & & \\
$900^{\circ} \mathrm{C}$ & 0.4 & 0.6 & 0.4 & 0.8 \\
$950^{\circ} \mathrm{C}$ & 0.6 & 0.8 & 0.5 & 0.9 \\
$1000^{\circ} \mathrm{C}$ & 1.0 & 0.9 & 0.5 & 1.0 \\
$1050^{\circ} \mathrm{C}$ & 0.8 & 0.8 & 0.3 & 0.9 \\
\hline Термостойкость, циклы & 1.0 & 1.2 & 0.6 & 1.2 \\
\hline Коэффициент теплопроводности, $\mathrm{BT} / \mathrm{M}^{\circ} \mathrm{C}$ & 0.617 & 0.420 & 0.300 & 0.383 \\
\hline
\end{tabular}
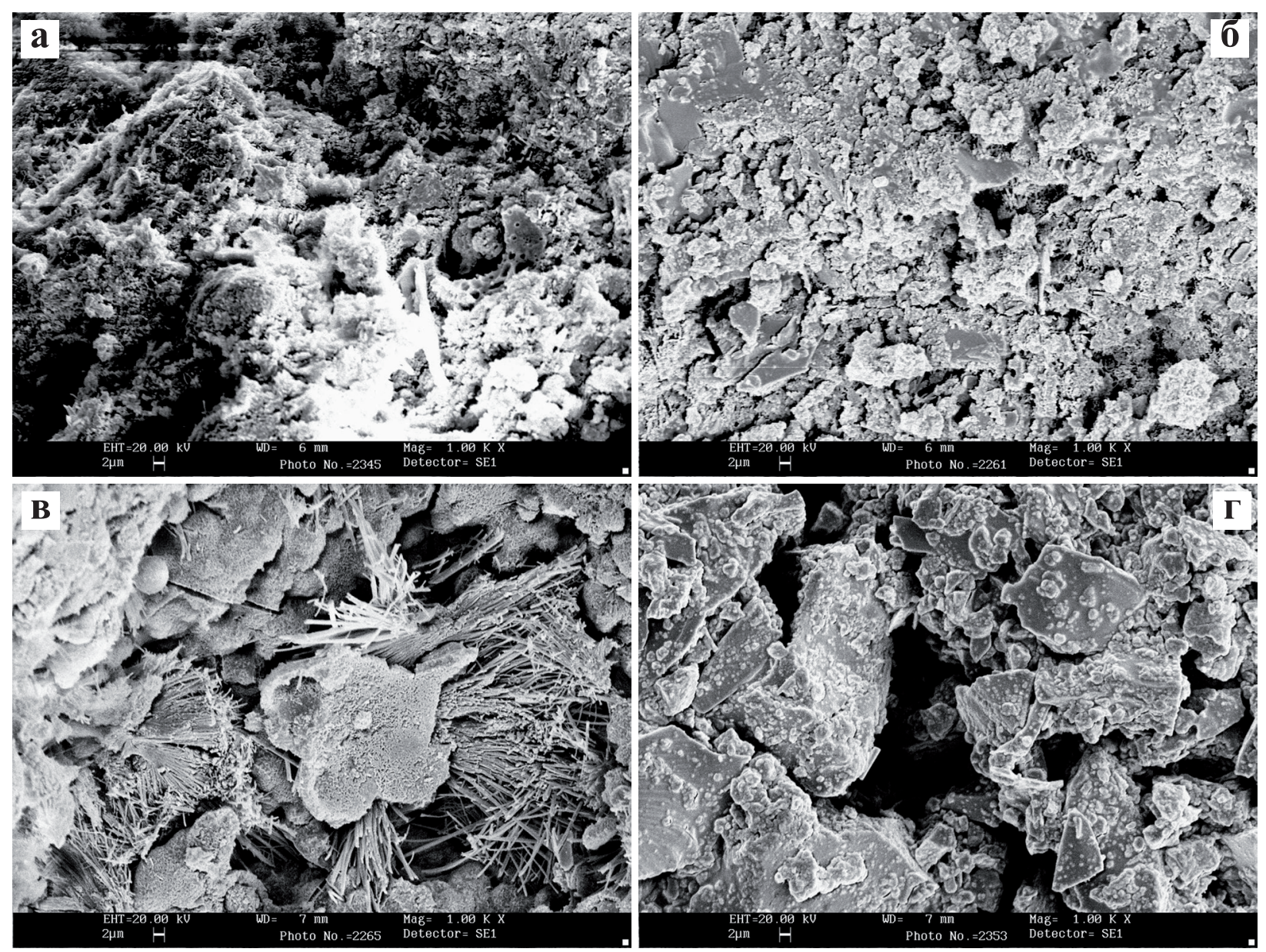

Рис. 2. Микроструктура бетона в возрасте 28 сут.

$\mathrm{a}$ - природный сланец; б, в, г - заполнитель, термообработанный при 950, 1000 и $1050^{\circ} \mathrm{C}$, соответственно.

Fig. 2. The microstructure of concrete at the age of 28 days.

$\mathrm{a}$ - natural slate; b, c, d-aggregate, heat-treated at 950,1000 and $1050^{\circ} \mathrm{C}$, respectively. 

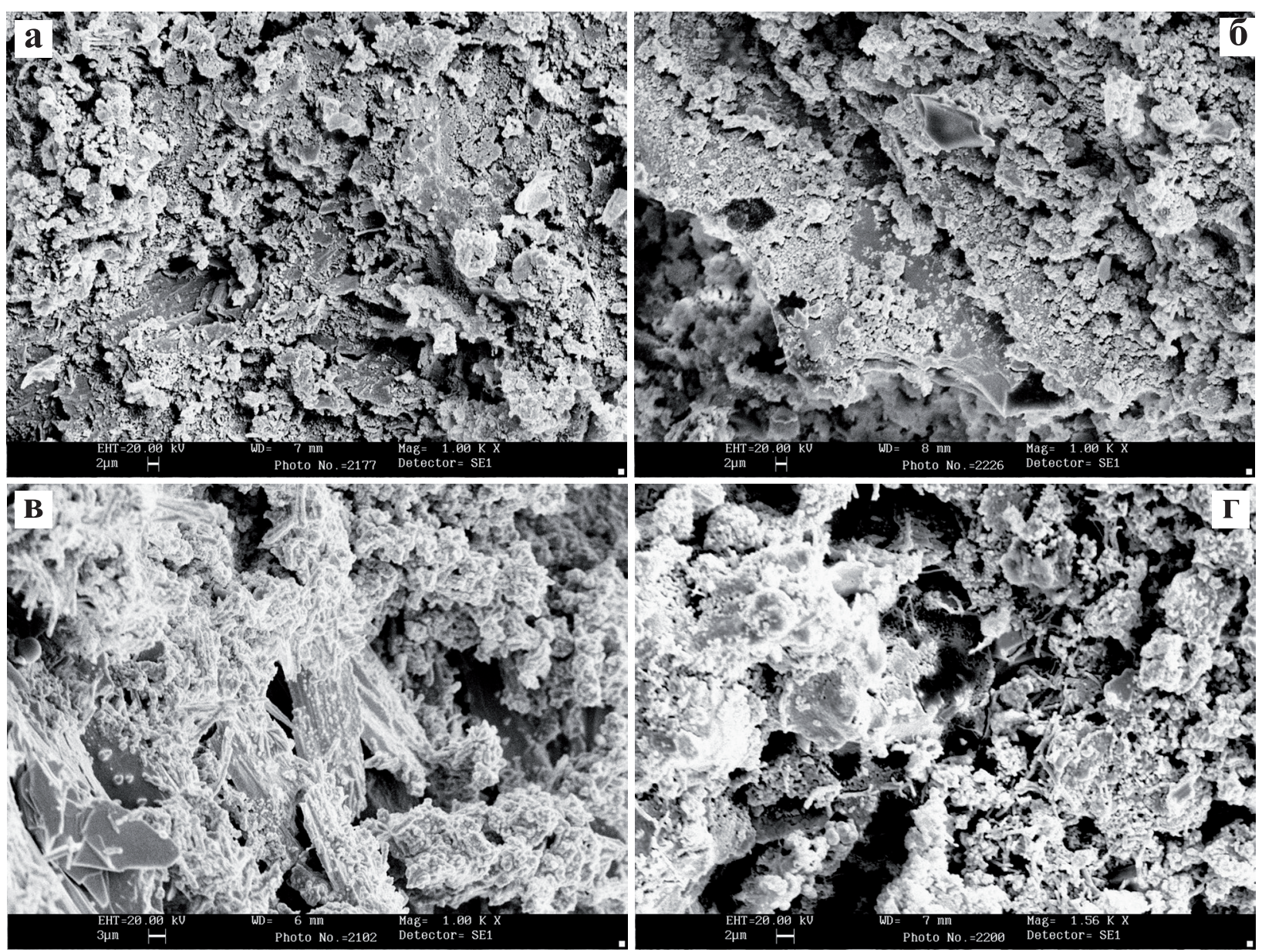

Рис. 3. Микроструктура жаростойкого бетона $\left(\mathrm{T}_{\text {обж. }}=800^{\circ} \mathrm{C}\right)$

a - природный сланец; б, в, г - заполнитель, термообработанный при 950, 1000 и $1050^{\circ} \mathrm{C}$, соответственно.

Fig. 3. Microstructure of heat-resistant concrete $\left(\mathrm{Tob} .=800^{\circ} \mathrm{C}\right)$. $\mathrm{a}$ - natural slate; b, c, d-aggregate, heat-treated at 950,1000 and $1050^{\circ} \mathrm{C}$, respectively.

Как видно из приведенных данных, наибольшие прочностные показатели имеет состав с заполнителем из обожженных при $1000^{\circ} \mathrm{C}$ сланцев. Класс бетона по прочности составляет В20. Также этот состав имеет самые высокие значения остаточной прочности $(58.6 \%)$ после нагрева до $800^{\circ} \mathrm{C}$ по сравнению с исходными необожженными сланцами и сланцами обожженными при более низких и более высоких температурах. Эти данные согласуются с результатами испытаний щебня, согласно которым щебень из сланцев, обожженных при $1000^{\circ} \mathrm{C}$, имеет наибольшую прочность.

Морфологические исследования подтверждают полученные результаты. На рисунке 2 представлены микрофотографии образцов бетона в возрасте 28 суток на термообработанных сланцах, позволяющие проследить изменение структуры бетона в зависимости от температуры обжига заполнителя.

Микроструктура бетона на природных сланцах и сланцах, обожженных при $900^{\circ} \mathrm{C}$ (рис. 2, а, б) характеризуется в основном рыхлой неоднородной структурой. На контакте цементного камня с гранулой природного сланца (рис. 2, а) четко выражена граница раздела фаз, что свидетельствует о недостаточной адгезии в зоне контакта. Микроструктура бетона на сланцах термообработанных при $1000^{\circ} \mathrm{C}$, отличается наличием (рис. 2, в) кристаллов пластинчатой и игольчатой формы, идентичных гидросиликатам и гидроалюминатам кальция, а также эттрингиту, армирующим поры цементного камня, способствуя тем самым увеличению прочностных свойств материала. При использовании заполнителя, термообработанного при $1050^{\circ} \mathrm{C}$ наблюдаются дефекты в контактной зоне «вяжущее - заполнитель», что прослеживается в виде образования зазора между цементным камнем и заполнителем (рис. 2, г). 
На долговечность жаростойкого бетона большое влияние оказывают его прочность после нагрева до $800^{\circ} \mathrm{C}$, так называемая остаточная прочность. Именно в это время происходит удаление влаги из бетона, стабилизируется его структура, наблюдается дегидратация минералов цементного камня, появляются большие структурные напряжения. В связи с этим $800^{\circ} \mathrm{C}$ является критической температурой и служит для контроля свойств жаростойкого бетона.

Микроструктура бетона после нагревания при $800^{\circ} \mathrm{C}$, показанная на рис. 3, подтверждает представленные в таблице 1 результаты по значениям остаточной прочности.

Так, бетон с заполнителем из термообработанных при $1000^{\circ} \mathrm{C}$ сланцев (рис. 3 , в), показывающий самые высокие значения остаточной прочности, имеет более развитую поверхность с новообразованиями из гидросиликатов и гидроалюминатов кальция, способствующих упрочнению структуры, по сравнению с бетоном на заполнителях, обожженных при более высокой и более низкой температурах (рис. 3, б, г).

Таким образом, установлено, что структура термообработанных сланцев оказывает существенное влияние на физико-химические свойства сланцев и жаростойких бетонов на их основе, что соответствует требованиям законов створа и конгруэнции. В результате термообработки сланцы приобретают шероховатую поверхность, которая обеспечивает хорошее сцепление между цементным камнем и заполнителем, повышая тем самым прочностные характеристики бетона.

\section{Литература}

1. Ильина В.П., Заверткин А.С., Анисимов А.М. Разработка технологии получения новых теплоизоляционных материалов для стационарных теплоаккумуляторов СТЭ типа «Печь» // Огнеупоры и техническая керамика. 2009. № 7-8. С. 81-86.

2. Соколов В.И. Талько-хлоритовые сланцы Карелии и пути их комплексного использования. Петрозаводск: Карельский научный центр РАН, 1995. 128 с.

3. Соколов В.И., Славин В.В., Зуев Н.М. Исследование талько-хлоритовых сланцев для футеровки алюминиевых электролизеров // Цветные металлы. 1993. № 5. С. 33-35.

4. Соколов В.И., Славин В.В., Зуев Н.М. Талько-хлоритовые сланцы и шунгиты в качестве новых футеровочных материалов // Цветные металлы. 1995. № 2. С. 31-34.

5. Талько-хлоритовые сланцы как сырье для получения керамической плитки / В.П. Ильина, Г.А. Лебедева, Г.П. Озерова, И.С. Инина // Материалы второй Международной научной конференции «Использование природного и техногенного сырья Баренцева региона в технологии строительных и технических материалов». Петрозаводск: Карельский НЦ РАН, 2005. С. 80-82. 